$12-19-2013$

\title{
Surgery for post-vitrectomy cataract
}

Diana V. Do

University of Nebraska Medical Center, diana.do@unmc.edu

Stephen Gichuhi

University of Nairobi

Satyanarayana S. Vedula

Johns Hopkins University

Barbara S. Hawkins

Johns Hopkins University

Tell us how you used this information in this short survey.

Follow this and additional works at: https://digitalcommons.unmc.edu/com_eye_articles

Part of the Ophthalmology Commons

\section{Recommended Citation}

Do, Diana V.; Gichuhi, Stephen; Vedula, Satyanarayana S.; and Hawkins, Barbara S., "Surgery for postvitrectomy cataract" (2013). Journal Articles: Ophthalmology. 14.

https://digitalcommons.unmc.edu/com_eye_articles/14

This Article is brought to you for free and open access by the Ophthalmology at DigitalCommons@UNMC. It has been accepted for inclusion in Journal Articles: Ophthalmology by an authorized administrator of DigitalCommons@UNMC.For more information, please contact digitalcommons@unmc.edu. 


\section{Surgery for post-vitrectomy cataract (Review)}

Do DV, Gichuhi S, Vedula SS, Hawkins BS

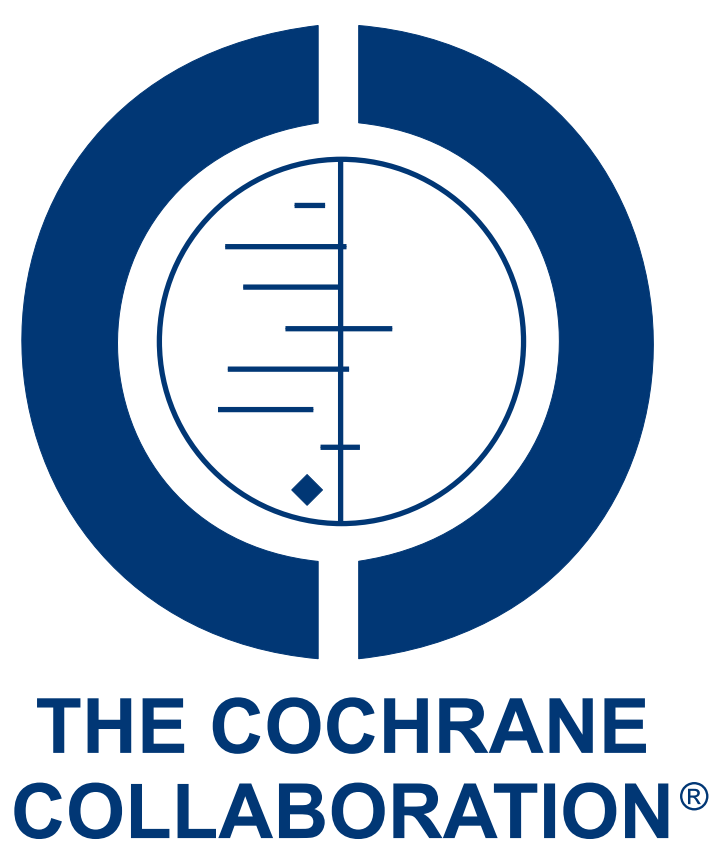

This is a reprint of a Cochrane review, prepared and maintained by The Cochrane Collaboration and published in The Cochrane Library 2013, Issue 12

http://www.thecochranelibrary.com

\section{WILEY}


TABLE OF CONTENTS

HEADER

ABSTRACT

PLAIN LANGUAGE SUMMARY

BACKGROUND

OBJECTIVES

METHODS

RESULTS

Figure 1.

DISCUSSION

AUTHORS' CONCLUSIONS

ACKNOWLEDGEMENTS

REFERENCES

CHARACTERISTICS OF STUDIES

DATA AND ANALYSES

APPENDICES

WHAT'S NEW

HISTORY

CONTRIBUTIONS OF AUTHORS

DECLARATIONS OF INTEREST

SOURCES OF SUPPORT

INDEX TERMS 


\title{
Surgery for post-vitrectomy cataract
}

\author{
Diana V Do ${ }^{1}$, Stephen Gichuhi ${ }^{2}$, Satyanarayana S Vedula ${ }^{3}$, Barbara S Hawkins ${ }^{4}$ \\ ${ }^{1}$ Stanley M. Truhlsen Eye Institute, University of Nebraska Medical Center, Omaha, Nebraska, USA. ${ }^{2}$ Department of Ophthalmology, \\ University of Nairobi, Nairobi, Kenya. ${ }^{3}$ Johns Hopkins University, Baltimore, Maryland, USA. ${ }^{4}$ Wilmer Eye Institute, Johns Hopkins \\ University School of Medicine, Baltimore, Maryland, USA \\ Contact address: Diana V Do, Stanley M. Truhlsen Eye Institute, University of Nebraska Medical Center, 3902 Leavenworth Street, \\ Omaha, Nebraska, 68105, USA. diana.do@unmc.edu.
}

Editorial group: Cochrane Eyes and Vision Group.

Publication status and date: New search for studies and content updated (no change to conclusions), published in Issue 12, 2013.

Review content assessed as up-to-date: 22 May 2013.

Citation: Do DV, Gichuhi S, Vedula SS, Hawkins BS. Surgery for post-vitrectomy cataract. Cochrane Database of Systematic Reviews 2013, Issue 12. Art. No.: CD006366. DOI: 10.1002/14651858.CD006366.pub3.

Copyright (C) 2013 The Cochrane Collaboration. Published by John Wiley \& Sons, Ltd.

\section{A B S T R A C T}

\section{Background}

Cataract formation or acceleration can occur after intraocular surgery, especially following vitrectomy, a surgical technique for removing the vitreous which is used in the treatment of disorders that affect the posterior segment of the eye. The underlying problem that led to vitrectomy may limit the benefit from cataract surgery.

\section{Objectives}

The objective of this review was to evaluate the effectiveness and safety of surgery for post-vitrectomy cataract with respect to visual acuity, quality of life, and other outcomes.

\section{Search methods}

We searched CENTRAL (which contains the Cochrane Eyes and Vision Group Trials Register) (The Cochrane Library 2013, Issue 4), Ovid MEDLINE, Ovid MEDLINE in-Process and Other Non-Indexed Citations, Ovid MEDLINE Daily Update, Ovid OLDMEDLINE (January 1946 to May 2013), EMBASE (January 1980 to May 2013, Latin American and Caribbean Health Sciences Literature Database (LILACS) (January 1982 to May 2013), PubMed (January 1946 to May 2013), the metaRegister of Controlled Trials ( $m$ RCT) (www.controlled-trials.com), ClinicalTrials.gov (www.clinicaltrial.gov) and the WHO International Clinical Trials Registry Platform (ICTRP) (www.who.int/ictrp/search/en). We did not use any date or language restrictions in the electronic searches for trials. We last searched the electronic databases on 22 May 2013.

\section{Selection criteria}

We planned to include randomized and quasi-randomized controlled trials comparing cataract surgery with no surgery in adult patients who developed cataract following vitrectomy.

\section{Data collection and analysis}

Two authors screened the search results independently according to the standard methodological procedures expected by The Cochrane Collaboration.

\section{Main results}

We found no randomized or quasi-randomized controlled trials comparing cataract surgery with no cataract surgery for patients who developed cataracts following vitrectomy surgery. 


\section{Authors' conclusions}

There is no evidence from randomized or quasi-randomized controlled trials on which to base clinical recommendations for surgery for post-vitrectomy cataract. There is a clear need for randomized controlled trials to address this evidence gap. Such trials should stratify participants by their age, the retinal disorder leading to vitrectomy, and the status of the underlying disease process in the contralateral eye. Outcomes assessed in such trials may include gain of vision on the Early Treatment Diabetic Retinopathy Study (ETDRS) scale, quality of life, and adverse events such as posterior capsular rupture. Both short-term (six-month) and long-term (one-year or twoyear) outcomes should be examined.

\section{PLAIN LANGUAGE SUMMARY}

\section{Surgery to remove cataracts after vitrectomy}

\section{Review question}

We reviewed the evidence about the effect of surgery to remove cataracts (cloudy lens in front of the eye) in people who develop cataracts after vitrectomy, a surgery to remove the vitreous (the clear gel) in the center of the eye.

\section{Background}

Vitrectomy, a procedure performed for disorders that affect the back part of the eye, can result in the formation or acceleration of cataract. The underlying problem that led to vitrectomy may limit the benefits from cataract surgery.

\section{Results}

We found no randomized controlled trials (trials in which participants are randomly assigned to one treatment group or another) that evaluated the benefits or risks (or both) of cataract surgery following vitrectomy. Since cataract surgery may lead to loss of vision due to worsening or recurrence of the condition that prompted the vitrectomy, its role in these patients remains uncertain. Future trials to address this review question should separate participants by age, the disorder leading to vitrectomy, and the status of the underlying disease process in the opposite eye. Outcomes relevant to patients such as improvement of vision and quality of life, and harms should be examined both in the short term (six months after surgery) and in the long term (one to two years after surgery).

\section{B A C K G R O U N D}

\section{Description of the condition}

Cataract, an opacification of the crystalline lens in the eye, can be caused by many factors including the natural aging process, metabolic abnormalities, nutritional disorders, chronic ocular inflammation, and trauma. The three types of cataract are classified according to the location of the opacity: cortical, nuclear sclerosis, and posterior subcapsular. Cataract formation or acceleration also can occur after intraocular surgery, especially following vitrectomy, a surgical technique for removing the vitreous that is used in the treatment of disorders that affect the posterior segment of the eye. Vitrectomy causes progression of nuclear sclerotic cataracts. Vitrectomy was first developed by Machemer in 1971 (Machemer 1971). It is a microsurgical technique in which specialized instru- ments and techniques are used to gain access to the vitreous cavity and retina. During vitrectomy surgery, three small incisions, each approximately $1.4 \mathrm{~mm}$ in length, are made in the eye in order to place instruments: a vitreous cutter, a fiberoptic light source to illuminate the inside of the eye, and an infusion cannula to maintain proper intraocular pressure during the surgery. During the past 40 years, advances in surgical technique and instrumentation have made vitrectomy a common surgical procedure for posterior segment disorders. Vitrectomy is indicated for numerous ocular conditions including vitreous loss in cataract surgery, subluxation of the lens, malignant glaucoma, dense pupillary membranes, nonclearing vitreous hemorrhage due to diabetic retinopathy or vein occlusions, retinal detachment, macular hole, macular pucker, vitreo-macular traction, and endophthalmitis.

Although vitrectomy has revolutionized the treatment of posterior segment disorders and improved visual outcomes in patients with 
retinal diseases requiring surgical intervention, vitrectomy also is associated with co-morbidities that may compromise visual acuity such as retinal detachment, corneal decompensation, and cataract formation or progression in phakic eyes (Benson 1988). The type of cataract that forms or accelerates after vitrectomy is nuclear sclerotic cataract. Cataract formation or progression is believed to be the most common complication associated with vitrectomy. In fact, in many eyes undergoing vitrectomy, the lens is removed at the same time. Often, the nuclear sclerotic cataracts that develop after vitrectomy limit visual acuity outcomes to a degree that would result in surgical removal of the lens in an otherwise 'normal' eye. The exact pathogenesis of cataract formation or acceleration after vitrectomy is unknown. Older studies have suggested that light toxicity, oxidation of lens proteins, use of intraocular gas, and length of operative time may be causative factors (Cherfan 1991; de Bustros 1988; Ogura 1991). Newer research suggests that vitrectomy surgery increases oxygen tension within the eye; oxygen exposure has been linked with progressive nuclear sclerotic cataract formation (Holekamp 2005; Palmquist 1988).

\section{Epidemiology}

Although cataract progression is common after vitrectomy, only a few prospective studies have evaluated this occurrence. Do and Hawkins performed a review (unpublished) of the pertinent literature in the PubMed database published from 1966 through 2005. A total of 51 studies were found. The majority of published studies on cataract progression after vitrectomy were retrospective analyses. The reported incidence of cataract was highly variable, from $6 \%$ to $100 \%$ of cases, depending upon the condition that prompted vitrectomy, duration of follow-up, and the method used to monitor development of cataract. These retrospective studies are limited by the non-uniformity of the lens grading system used or the absence of a description of the lens grading system in the published report.

The Vitrectomy for Macular Hole Study, a randomized controlled trial that evaluated vitrectomy for the treatment of macular holes, retrospectively examined the incidence of cataract development among 74 eyes of patients that participated in the study (Cheng 2001). Investigators used a scoring system similar to the Lens Opacities Classification System II, which contains five grading categories for nuclear and posterior subcapsular opacities. Although duration of surgery did not increase the risk for cataract progression, vitrectomy itself was a risk factor for cataract acceleration; 60/ $74(81 \%)$ eyes in the surgery cohort had nuclear sclerotic cataract progression at six months of follow-up, compared to only 13/74 (18\%) fellow eyes in the control group. By two years, $100 \%$ of eyes in the surgery cohort had cataract progression, compared to $8 \%$ of control eyes. Similarly, Cherfan and colleagues retrospectively reviewed 100 eyes after vitrectomy for idiopathic macular pucker (Cherfan 1991). After an average follow-up of 29 months (range six to 99 months), 80/100 (80\%) eyes in the vitrectomy group and only 24/100 (24\%) fellow eyes had developed a visually significant nuclear sclerotic cataract or had undergone cataract extraction.

During the late 1990s, the Submacular Surgery Trials (SST) were initiated to evaluate surgical removal of subfoveal choroidal neovascularization $(\mathrm{CNV})$ compared with observation in patients with age-related macular degeneration (AMD) (SST Group N and Group B), ocular histoplasmosis syndrome (OHS) (SST Group H), and idiopathic CNV (SST Group H) (SST 2004a; SST 2004b; SST 2004c). In these three randomized controlled trials, visually significant cataract was defined as either cataract surgery or lens opacity reported by the SST ophthalmologist to be sufficient to reduce visual acuity by two or more lines in a normal eye. Among the AMD participants in the SST Group N study, $80 \%$ of eyes assigned to vitrectomy and surgical removal of their subfoveal CNV developed visually significant cataracts at two years of follow-up. Sixty per cent of eyes had undergone cataract surgery by their last follow-up examination two to four years after enrollment. Among the OHS participants in the SST Group H study, 39\% of eyes assigned to vitrectomy developed visually significant cataracts, among which $24 \%$ underwent cataract removal. The difference between eyes with AMD and eyes with OHS developing postvitrectomy cataract is likely due to the median age of the patients. Patients under the age of 50 years are less likely to develop postsurgical accelerated nuclear sclerosis (Melberg 1995). Data from the SST provide the largest and most complete follow-up of eyes undergoing vitrectomy that are at high risk for developing visually significant post-surgical nuclear sclerotic cataracts.

\section{Presentation and diagnosis}

Patients who develop post-vitrectomy cataract present with decreased visual acuity despite anatomic or functional success (or both) of the vitrectomy surgery. Individuals who have undergone vitrectomy may have lower levels of baseline (pre-cataract) visual acuity due to the underlying nature of their retinal pathology; therefore patients with post-vitrectomy cataract are more likely to present with poorer vision than individuals with typical senile cataracts. Diagnosis is made with ocular examination using slitlamp biomicroscopy.

\section{Description of the intervention}

Cataract surgery, typically using phacoemulsification and intraocular lens implantation, is commonly recommended for individuals with visually significant lens opacities. Two features of postvitrectomy nuclear sclerosis make affected lenses especially challenging for cataract surgeons to remove. The nucleus tends to be harder than in age-related nuclear sclerosis, requiring longer phacoemulsification time during the procedure. Also, the absence of vitreous in the posterior segment allows for more mobility of the posterior capsule, increasing the risk of capsular rupture. Thus, surgery for post-vitrectomy nuclear sclerotic cataract may have a 
higher incidence of complications, although evidence from comparative studies is lacking (Ahfat 2003; Biro 2002).

\section{How the intervention might work}

Patients who develop cataract after vitrectomy may undergo cataract extraction; however, visual acuity and other outcomes after cataract surgery may be poor due to the underlying retinal disorder. Most patients who have vitrectomy surgery have serious underlying problems, as indicated by the reasons for vitrectomy. Furthermore, eyes with post-vitrectomy cataract are at risk of complications that affect all eyes that undergo cataract surgery such as endophthalmitis, cystoid macular edema, etc. Thus, vision is often already impaired before cataract surgery and may remain impaired after cataract surgery. Although cataract surgery in a normal eye typically improves vision, the visual prognosis after surgery for post-vitrectomy cataract is uncertain. It likely depends on the success of treatment for the retinal disorder and avoidance of complications during cataract surgery.

\section{Why it is important to do this review}

The incidence of cataract formation after vitrectomy varies widely and has been reported to be between $6 \%$ and $100 \%$. The majority of published studies confirm that a high rate of cataract formation occurs, but few data are available on visual acuity outcomes after cataract removal. The retinal problem that led to vitrectomy may progress or recur. However, peer-reviewed data on outcomes after surgery for post-vitrectomy cataract are scarce. Even in situations in which cataract formation is not due to vitrectomy, visual impairment can still exist despite cataract extraction. The Los Angeles Latino Eye Study (Barañano 2007) published visual acuity outcomes after cataract extraction in adult Latinos and reported that $41 \%$ of eyes had visual impairment (defined as a best-corrected visual acuity of 20/40 Snellen equivalent or less). Age-related macular degeneration and diabetic retinopathy accounted for approximately $57 \%$ of retinal pathology after cataract extraction. In addition, in eyes that have undergone vitrectomy surgery the absence of vitreous in the posterior segment allows for more mobility of the posterior capsule, increasing the risk of capsular rupture. Surgery for post-vitrectomy nuclear sclerotic cataract may have a higher incidence of complications. A systematic review of outcomes from controlled clinical trials would provide information for adequate counseling of patients and for guiding ophthalmologists' recommendations.

\section{O B J E C T I V E S}

The objective of this review was to evaluate the effectiveness and safety of surgery for post-vitrectomy cataract with respect to visual acuity, quality of life, and other outcomes.

\section{METHODS}

\section{Criteria for considering studies for this review}

\section{Types of studies}

We planned to include both randomized and quasi-randomized controlled trials in this review. We considered quasi-randomized trials to be trials that had adopted a method of allocation intended to allocate patients in a random fashion but were not strictly random. Examples include allocation by date of birth, social security number, etc. We were to include trials with at least six months' follow-up to allow for reporting of early adverse effects, even though we planned our primary analyses to focus on outcomes at the end of one year of follow-up.

\section{Types of participants}

We planned to include trials that enrolled adult participants (age 18 years and over) with cataract that had developed after vitrectomy for any indication except for trauma. However, we planned not to exclude trials that included both adult patients who had post-traumatic vitrectomy and patients who had other indications for vitrectomy, except when outcomes were reported separately by indication. We planned to exclude trials that included only trauma cases, because these patients typically are younger and the pathogenesis of cataract formation is different.

\section{Types of interventions}

We planned to include trials that compared cataract surgery (of any type) with no surgery in such patients.

\section{Types of outcome measures}

\section{Primary outcomes}

Visual acuity improvement after cataract surgery of at least three letters on a logMAR chart, one line on the Snellen chart, or equivalent changes on other scales. While we planned to analyze the outcomes at one year, two years, and at longer time points of follow-up as available from included studies, our primary analysis was to focus on one-year follow-up. 


\section{Secondary outcomes}

1. Quality of life measured by a validated scale.

2. Contrast sensitivity: improvement of at least one level, regardless of the manner in which it was measured in included trials.

3. Progression of the condition that was the original indication for vitrectomy in patients with diabetic retinopathy (DR) and age-related macular degeneration (AMD) as defined by standard grading scales such as the Diabetic Retinopathy Scale for DR (ETDRS 1991) and the International Scale for AMD (Bird 1995).

\author{
Adverse outcomes \\ Specific adverse effects of interest included: \\ - cystoid macular edema; \\ - intraocular lens-related complications, including \\ dislocation, difficulty in placing the lens; \\ - capsular opacification; \\ - retinal detachment (new or recurrent).
}

We also planned to summarize all other adverse effects reported in included studies.

\section{Economic outcomes}

We planned to tabulate or summarize data on the costs of procedures, consequences of complications, and any cost-effectiveness data reported in included studies in a narrative fashion.

\section{Search methods for identification of studies}

\section{Electronic searches}

In 2013, we revised the searches of electronic databases from the 2011 update. We searched PubMed and the International Clinical Trials Registry Platform, which had not originally been searched. We searched the Cochrane Central Register of Controlled Trials (CENTRAL) (which contains the Cochrane Eyes and Vision Group Trials Register) 2013, Issue 4, part of The Cochrane Library. www.thecochranelibrary.com (accessed 22 May 2013), Ovid MEDLINE, Ovid MEDLINE In-Process and Other Non-Indexed Citations, Ovid MEDLINE Daily Update, Ovid OLDMEDLINE (January 1946 to August 2013), EMBASE (January 1980 to May 2013), Latin American and Caribbean Health Sciences Literature Database (LILACS) (January 1982 to May 2013), the metaRegister of Controlled Trials ( $m$ RCT) (www.controlled-trials.com), ClinicalTrials.gov ( www.clinicaltrial.gov), the WHO International Clinical Trials Registry Platform (ICTRP) (www.who.int/ictrp/search/en) and PubMed (January 1956 to May 2013). We did not use any date or language restrictions in the electronic searches for trials. We last searched the electronic databases on 22 May 2013.

See: Appendices for details of search strategies for CENTRAL (Appendix 1), MEDLINE (Appendix 2), EMBASE (Appendix 3), LILACS (Appendix 4), $m$ RCT (Appendix 5), ClinicalTrials.gov (Appendix 6), ICTRP (Appendix 7) and PubMed (Appendix 8). The UK Clinical Research Network Portfolio Database and the Australian New Zealand Clinical Trials Registry are no longer being searched for this review.

\section{Searching other resources}

We planned to search the reference lists of included studies and the Science Citation Index - Expanded database to identify any additional trials. We did not search any conference proceedings specifically for the purpose of this review.

\section{Data collection and analysis}

\section{Selection of studies}

Two review authors independently screened the titles and abstracts of all records identified in the electronic and manual searches. We labeled each record as 'A - include', 'B - unsure', or 'C - exclude'. Two authors then screened the full reports of records labeled ' $\mathrm{B}$ unsure'; we relabeled each record as 'A - include' or ' $\mathrm{C}$ - exclude' based on consensus after review. We listed studies reported in records labeled ' $\mathrm{C}$ - exclude' after full-text review in the table of excluded studies with reasons for exclusion. We planned to assess methodological quality for studies labeled as 'A - include'; however, we did not identify any study labeled as 'A - include' by either of the two review authors.

We found no trials eligible for inclusion in either the original review or the updated review. The methods described below will be applicable to future updates of the review when trials eligible for inclusion have been conducted and reported.

\section{Data extraction and management}

Two review authors will independently extract data on basic characteristics of each study (including details of study design, characteristics of participants, interventions, and comparators) and the primary and secondary outcomes onto data collection forms developed in collaboration with the Cochrane Eyes and Vision Group. We will resolve discrepancies by discussion. We will contact authors of included studies for missing data. One review author will enter all data into RevMan 5.2 (RevMan 2013) and another author will verify the data. 


\section{Assessment of risk of bias in included studies}

Two review authors, working independently, will assess the included studies for sources of systematic bias according to the guidelines in Chapter 8 of the Cochrane Handbook for Systematic Reviews of Interventions (Higgins 2011a). We will evaluate studies for the following criteria: method of randomization, allocation concealment (selection bias), masking of outcome assessment, completeness of outcome data and intention-to-treat analysis (attrition bias), and other potential sources of bias including source of trial funding. We will not assess masking of investigators as the interventions to be compared preclude such efforts. Though an artificial lens placed in the eyes of patients in the intervention group may be recognized by the anatomic outcome assessor, visual acuity testing may have been performed by someone not responsible for examining the eye. Also, quality of life data may have been collected by some method that preserves masking of intervention or outcome assessment, or both. We will judge each criterion as either 'low risk of bias', 'high risk of bias', or 'unclear risk of bias'. We will use information in the Cochrane Handbook for Systematic Reviews of Interventions to guide our judgment for each criterion. We will contact authors of studies labeled 'unsure' for clarification. Differences between the two review authors will be resolved by discussion.

\section{Measures of treatment effect}

We will calculate a summary risk ratio for dichotomous outcomes (visual acuity improvement, progression of the condition that was the original indication for vitrectomy, and adverse events). We will calculate the mean difference for continuous outcomes (quality of life, cost-effectiveness, and contrast sensitivity).

\section{Unit of analysis issues}

The unit of analysis will be the eye for vision-related outcomes (visual acuity, contrast sensitivity, progression, and adverse events). For quality of life and economic outcomes, the unit of analysis will be the person.

\section{Dealing with missing data}

We will attempt to contact the investigators of included trials for any missing data. If the investigators do not respond within four weeks, we will extract available data from the published report. We will refer to the guidelines in Chapter 16 of the Cochrane Handbook for Systematic Reviews of Interventions (Higgins 2011b) for handling missing data.

\section{Assessment of heterogeneity}

We will examine the design and clinical heterogeneity among included studies by carefully analyzing their characteristics. We also will examine the degree of overlap in the confidence intervals of the studies. If there is poor overlap, this will be taken to indicate the presence of statistical heterogeneity. We will test for statistical heterogeneity formally using the $\mathrm{Chi}^{2}$ test. We also will use the I 2 statistic value to determine the proportion of variation due to heterogeneity among studies, and will consider an $\mathrm{I}^{2}$ value greater than $50 \%$ to indicate substantial statistical heterogeneity.

\section{Assessment of reporting biases}

We will examine a funnel plot to identify any evidence of publication bias when a sufficient number of studies are included, i.e., 10 or more.

\section{Data synthesis}

If no significant heterogeneity is detected, either statistically or if there is a small number of trials in the analysis (three or fewer), we will use a fixed-effect model. If the number of trials is greater than three and no heterogeneity has been detected, we will use a random-effects model.

If significant heterogeneity has been detected, we will not combine results to produce a single summary measure. In this case, we will describe the forest plot in the results section of the review.

\section{Subgroup analysis and investigation of heterogeneity}

We will investigate heterogeneity, if present, through subgroup analyses. If sufficient data are available, we will conduct subgroup analyses based on the agents used to fill the vitreous space after vitrectomy, e.g., air, different gases, and by different indications for vitrectomy.

\section{Sensitivity analysis}

We will conduct sensitivity analyses to determine the impact of exclusion of studies of lower methodological quality, including quasi-randomized trials, and exclusion of industry-funded studies and unpublished studies.

\section{RES U L T S}

\section{Description of studies}

\section{Results of the search}

The original electronic searches retrieved a total of 1949 references and 29 additional records from clinical trials registers. After 
independent review of the titles and abstracts by two review authors, we retrieved 36 full-text articles. We found no randomized or quasi-randomized trials eligible for inclusion in the review. An updated search was done in April 2011; we retrieved 785 references and 18 additional records from clinical trials registers. We assessed the records but none were eligible for inclusion in the review.

The most recent updated search conducted in May 2013 yielded 1009 references and 120 additional records from clinical trials registers. We assessed the records but none were eligible for inclusion in the review (Figure 1). During the process of the most recent update, we also re-assessed the eligibility for all previously excluded studies, and removed 22 out of 36 references from the list by reviewing titles and abstracts. All of the 22 references were either non-human study or non randomized controlled trials. We still kept the reasons for exclusion for the remaining 14 references for 10 studies in the 'Characteristics of excluded studies' table.

Figure I. Study flow diagram.

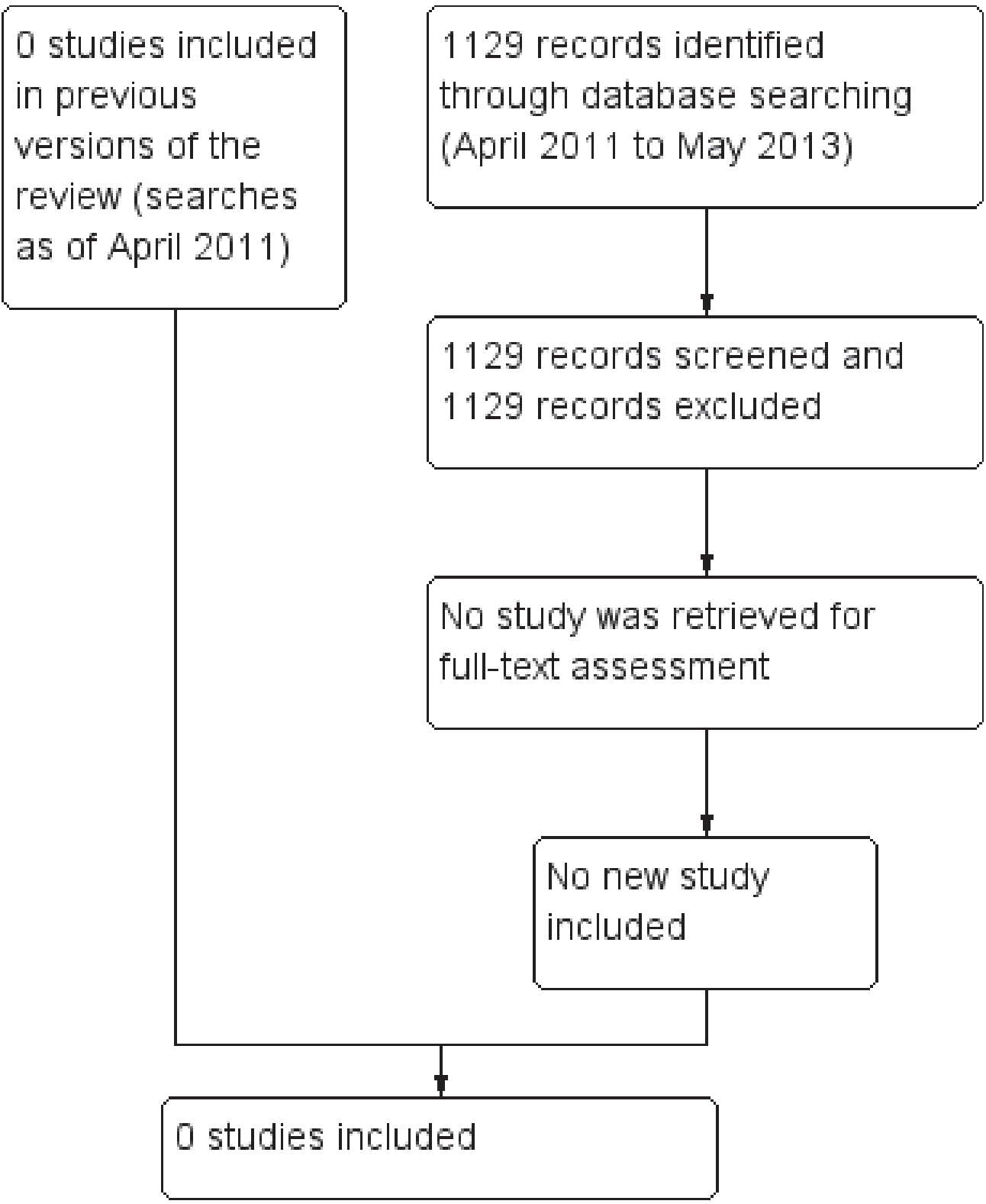

Surgery for post-vitrectomy cataract (Review) 


\section{Included studies}

We did not identify any studies eligible for inclusion in this review.

\section{Excluded studies}

Review of the full-text articles did not identify any studies that are relevant to the objective of this systematic review.

\section{Risk of bias in included studies}

We found no trials eligible for inclusion in the review for assessment of risk of bias.

\section{Effects of interventions}

We found no information on effects of interventions from trials eligible for inclusion in the review.

\section{DISCUSSION}

The majority of the published literature on this subject is limited to retrospective case reports or non-randomized prospective case series (Ahfat 2003). Any attempt to draw conclusions from these non-randomized studies would be misleading. In addition, there is no reliable method to identify all observational studies on this topic; therefore data collection is likely to be incomplete. Thus, our protocol specifically stated that we were interested in outcomes based on randomized or quasi-randomized clinical trials, not observational studies. This dearth of information on surgery for post-vitrectomy cataract indicates that information on this topic is needed, as thousands of patients undergo vitrectomy each year and are at risk of development of cataract and cataract surgery. Documentation of both the risks and benefits of surgery for postvitrectomy cataract is needed to inform patient counseling and clinical recommendations.

\section{A U THORS' CONCLUSIONS}

\section{Implications for practice}

In the absence of data from controlled trials, ophthalmologists have no reliable evidence to use when counseling patients regarding the risks and benefits of surgery for post-vitrectomy cataract, and no basis for recommendations for or against cataract surgery or when to intervene surgically. It is possible that some of the complications of surgery for post-vitrectomy cataract could be reduced if surgery were known to be beneficial and to be beneficial if performed at an early stage of development of nuclear sclerosis. Data from retrospective studies are inadequate for these purposes.

\section{Implications for research}

There is a clear need for well-designed randomized controlled trials to evaluate the benefits and risks of surgery for cataracts that develop following vitrectomy. We recommend that randomization in such trials be stratified by patients' age, retinal disorder leading to vitrectomy, and status of the pathologic process in the contralateral eye. Because patients who undergo vitrectomy already have reduced vision due to the underlying condition that prompted vitrectomy, relevant outcomes such as quality of life should be considered in addition to visual acuity and other clinical measures of vision. We recommend that restoration or gain of eight or more letters vision on the ETDRS scale with cataract surgery would be a reasonable expectation in this patient population. Analyses should include both short-term (six months) and long-term (one-year to two-year) outcomes. Data on adverse outcomes, including complications of surgery such as posterior capsular rupture, should be documented in future trials.

However, there are ethical difficulties in conducting a randomized trial of surgery for post-vitrectomy cataract. Observation of progression of post-vitrectomy cataract may not be considered an ethical alternative. In certain patient populations, such as those with significant central vision loss due to macular scars, observation of post-vitrectomy cataract may be ethical, and conducting a randomized controlled trial to determine if cataract surgery improves quality of life may be a reasonable option. One possible trial design would be to enroll patients over the age of 50 years who are scheduled for vitrectomy, who do not have visually significant cataract in the study eye, and who have visual acuity better than 20/40 in the fellow eye in a two-stage RCT. The initial randomization would be between vitrectomy alone and vitrectomy plus lens removal. Any cataract surgery in the fellow eye would be deferred for at least six months. At six months, study eyes in the deferred group in which visually significant cataract had developed would then be randomized to cataract surgery or deferment for another six months. At the end of the second six-month period, all patients with visually significant cataract in the study eye could be offered surgery. This design would permit evaluation of:

- time to development or progression of cataract in the initial vitrectomy only arm;

- time to progression or recurrence of the underlying retinal problem that led to vitrectomy in the two initial treatment arms;

Surgery for post-vitrectomy cataract (Review) 
- comparison of quality of life between the two arms of the original randomization; and

- (with the second randomization) comparison of the above outcomes with and without cataract surgery.

This design would take account of the large number of patients who have lens surgery at the time of vitrectomy and might support that practice or suggest that it was desirable only in selected subgroups of patients, as long as the fellow eye had useful vision.

Concerns about surgical complications, prognosis for recovery of visual acuity, and uncertainty regarding progression of underlying retinal disorder, are important considerations in establishing equipoise necessary for randomization. Further, insufficient infor- mation on outcomes important to patients, such as vision-related quality of life, indicates an inability to reasonably assess risks and benefits of surgery for post-vitrectomy cataract.

\section{ACKNOWLEDGEMENTS}

We thank Iris Gordon, Trials Search Co-ordinator for the Cochrane Eyes and Vision Group, for designing and conducting the electronic searches. We thank Marie Diener-West for her comments on the protocol and Nancy Holekamp and Roberta Scherer for their comments on the review. The CEVG methodologist Xue Wang $(\mathrm{XW})$ and the Editorial team provided co-ordination and support.

\section{R E F E R E N C E S}

\section{References to studies excluded from this review}

Ahmadieh 2005 \{published data only\}

Ahmadieh H, Moradian S, Faghihi H, Parvaresh MM, Ghanbari H, Mehryar M, et al.Anatomic and visual outcomes of scleral buckling versus primary vitrectomy in pseudophakic and aphakic retinal detachment: sixmonth follow-up results of a single operation--report no. 1 . Ophthalmology 2005;112(8):1421-9.

Asaria 2001 \{published data only\}

Asaria RH, Kon CH, Bunce C, Charteris DG, Wong D, Khaw PT, et al.Adjuvant 5-fluorouracil and heparin prevents proliferative vitreoretinopathy: results from a randomized, double-blind, controlled clinical trial. Ophthalmology 2001; 108(7):1179-83.

Batman 1999 \{published data only\}

Batman C, Cekic O. Vitrectomy with silicone oil or longacting gas in eyes with giant retinal tears: long-term followup of a randomized clinical trial. Retina 1999;19(3): 188-92.

Blankenship 1980 \{published data only\} Blankenship GW. The lens influence on diabetic vitrectomy results. Report of a prospective randomized study. Archives of Ophthalmology 1980;98(12):2196-8.

DRVS 1985 \{published data only\}

The Diabetic Retinopathy Vitrectomy Study Research Group. Early vitrectomy for severe proliferative diabetic retinopathy in eyes with useful vision. Results of a randomized trial--Diabetic Retinopathy Vitrectomy Study Report 3. The Diabetic Retinopathy Vitrectomy Study Research Group. Ophthalmology 1988;95(10):1307-20. The Diabetic Retinopathy Vitrectomy Study Research Group. Early vitrectomy for severe vitreous hemorrhage in diabetic retinopathy. Four-year results of a randomized trial:
Diabetic Retinopathy Vitrectomy Study Report 5. Archives of Ophthalmology 1990;108(7):958-64.

The Diabetic Retinopathy Vitrectomy Study Research Group. Early vitrectomy for severe vitreous hemorrhage in diabetic retinopathy. Two-year results of a randomized trial. Diabetic Retinopathy Vitrectomy Study report 2. The Diabetic Retinopathy Vitrectomy Study Research Group. Archives of Ophthalmology 1985;103(11):1644-52.

Ehud 1988 \{published data only\}

Ehud A, Varda C, Joseph M, Giora T. Management of complicated retinal detachment by vitrectomy and silicone oil injection. Metabolic, Pediatric, and Systemic Ophthalmology 1988;11(1-2):63-6.

Ezra 2004 \{published data only\} Ezra E, Gregor ZJ. Surgery for idiopathic full-thickness macular hole: two-year results of a randomized clinical trial comparing natural history, vitrectomy, and vitrectomy plus autologous serum: Morfields Macular Hole Study Group RAeport no. 1. Archives of Ophthalmology 2004;122(2): 224-36.

Freeman 1997 \{published data only\} Freeman WR, Azen SP, Kim JW, el-Haig W, Mishell DR 3rd, Bailey I. Vitrectomy for the treatment of full-thickness stage 3 or 4 macular holes. Results of a multicentered randomized clinical trial. The Vitrectomy for Treatment of Macular Hole Study Group. Archives of Ophthalmology 1997;115(1):11-21.

Haimann 1984 \{published data only\} Haimann MH, Abrams GW. Prevention of lens opacification during diabetic vitrectomy. Ophthalmology 1984;91(2):116-21.

Silicone Study 1992 \{published data only\} Abrams GW, Azen SP, McCuen BW 2nd, Flynn HW Jr, Lai MY, Ryan SJ. Vitrectomy with silicone oil or long-acting gas in eyes with severe proliferative vitreoretinopathy: results of 
additional and long-term follow-up. Silicone Study report 11. Archives of Ophthalmology 1997;115(3):335-44. Anonymous. Vitrectomy with silicone oil or perfluoropropane gas in eyes with severe proliferative vitreoretinopathy: results of a randomized clinical trial. Silicone Study Report 2. Archives of Ophthalmology 1992; 110(6):780-92.

Anonymous. Vitrectomy with silicone oil or sulfur hexafluoride gas in eyes with severe proliferative vitreoretinopathy: results of a randomized clinical trial. Silicone Study Report 1. Archives of Ophthalmology 1992; 110(6):770-9.

\section{Additional references}

\section{Ahfat 2003}

Ahfat FG, Yuen CH, Groenewald CP. Phacoemulsification and intraocular lens implantation following pars plana vitrectomy: a prospective study. Eye 2003;17(1):16-20.

\section{Barañano 2007}

Barañano AE, Wu J, Mazhar K, Azen SP, Varma R, Los Angeles Latino Eye Study Group. Visual acuity outcomes after cataract extraction in adult Latinos. The Los Angeles Latino Eye Study. Ophthalmology 2008;115(5):815-21.

\section{Benson 1988}

Benson WE. Vitrectomy in clinical ophthalmology. In: Duane TD editor(s). Duanés Clinical Ophthalmology. Vol. 5, Philadelphia: Lippincott, 1988:15-7.

\section{Bird 1995}

Bird AC, Bressler NM, Bressler SB, Chisholm IH, Coscas G, Davis $\mathrm{MD}$, et al.An international classification and grading system for age-related maculopathy and age-related macular degeneration. The International ARM Epidemiological Study Group. Survey of Ophthalmology 1995;39(5):367-74.

\section{Biro 2002}

Biro Z, Kovacs B. Results of cataract surgery in previously vitrectomized eyes. Journal of Cataract and Refractive Surgery 2002;28(6):1003-6.

\section{Cheng 2001}

Cheng L, Azen SP, El-Bradey MH, Scholz BM, Chaidhawangul S, Toyoguchi M, et al.Duration of vitrectomy and postoperative cataract in the vitrectomy for macular hole study. American Journal of Ophthalmology 2001;132(6):881-7.

\section{Cherfan 1991}

Cherfan GM, Michels RG, de Bustros S, Enger C, Glaser BM. Nuclear sclerotic cataract after vitrectomy for idiopathic epiretinal membranes causing macular pucker. American Journal of Ophthalmology 1991;111(4):434-8.

\section{de Bustros 1988}

de Bustros S, Thompson JT, Michels RG, Enger C, Rice TA, Glaser BM. Nuclear sclerosis after vitrectomy for idiopathic epiretinal membrane. American Journal of Ophthalmology 1988;105(2):160-4.

\section{ETDRS 1991}

Anonymous. Fundus photographic risk factors for progression of diabetic retinopathy. ETDRS report number 12. Early Treatment Diabetic Retinopathy Study Research Group. Ophthalmology 1991;98(Suppl 5):823-33.

\section{Higgins 2011a}

Higgins JPT, Altman DG, Sterne JAC (editors). Chapter 8: Assessing risk of bias in included studies. In: Higgins JPT, Green S (editors). Cochrane Handbook for Systematic Reviews of Interventions Version 5.1.0 (updated March 2011). The Cochrane Collaboration, 2011. Available from www.cochrane-handbook.org.

\section{Higgins 2011b}

Higgins JPT, Deeks JJ, Altman DG (editors). Chapter 16: Special topics in statistics. In: Higgins JPT, Green $S$ (editors), Cochrane Handbook for Systematic Reviews of Interventions Version 5.1.0 (updated March 2011). The Cochrane Collaboration, 2011. Available from www.cochrane-handbook.org.

\section{Holekamp 2005}

Holekamp NM, Shui YB, Beebe DC. Vitrectomy surgery increases oxygen exposure to the lens: a possible mechanism for nuclear cataract formation. American Journal of Ophthalmology 2005;139(2):302-10.

\section{Machemer 1971}

Machemer R, Buettner H, Norton EWD, Parel JM. Vitrectomy: A pars plana approach. Transactions of the American Academy of Ophthalmology and Otolaryngology 1971;75(4):813-20.

\section{Melberg 1995}

Melberg NS, Thomas MA. Nuclear sclerotic cataract after vitrectomy in patients under 50 years of age. Ophthalmology 1995;102(10):1466-71.

\section{Ogura 1991}

Ogura Y, Takanashi T, Ishigooka H, Ogino N. Quantitative analysis of lens changes after vitrectomy by fluorophotometry. American Journal of Ophthalmology 1991;111(2):179-83.

Palmquist 1988 Palmquist BM, Philipson B, Fagerholm P. Nuclear cataract a microradiographic study. Acta Ophthalmologica 1988;66 (6):671-7.

\section{RevMan 2013}

The Nordic Cochrane Centre, The Cochrane Collaboration. Review Manager (RevMan). 5.2. Copenhagen: The Nordic Cochrane Centre, The Cochrane Collaboration, 2013.

\section{SST 2004a}

Hawkins BS, Bressler NM, Miskala PH, Bressler SB, Holekamp NM, Marsh MJ, et al.Surgery for subfoveal choroidal neovascularization in age-related macular degeneration: ophthalmic findings: SST report no.11. Ophthalmology 2004;111(11):1967-80.

\section{SST 2004b}

Bressler NM, Bressler SB, Childs AL, Haller JA, Hawkins BS, Lewis $\mathrm{H}$, et al.Surgery for hemorrhagic choroidal 
neovascular lesions of age-related macular degeneration: Ophthalmic findings. SST report no. 13. Ophthalmology 2004;111(11):1993-2006.

\section{SST 2004c}

Hawkins BS, Bressler NM, Bressler SB, Davidorf FH, Hoskins JC, Marsh MJ, et al.Surgical removal vs observation for subfoveal choroidal neovascularization, either associated with the ocular histoplasmosis syndrome or idiopathic: I. Ophthalmic findings from a randomized clinical trial: Submacular Surgery Trials (SST) Group H Trial: SST Report No. 9. Archives of Ophthalmology 2004;122(11): 1597-611.

\section{References to other published versions of this review}

Do 2007

Do DV, Hawkins BS, Gichuhi S. Surgery for postvitrectomy cataract. Cochrane Database of Systematic Reviews 1, Issue 2007. [DOI: 10.1002/14651858.CD006366]

Do 2008

Do DV, Hawkins B, Gichuhi S, Vedula SS. Surgery for post-vitrectomy cataract. Cochrane Database of Systematic Reviews 2008, Issue 3. [DOI: 10.1002/ 14651858.CD006366.pub2]

* Indicates the major publication for the study 


\section{CHARACTERISTICS OF STUDIES}

Characteristics of excluded studies [ordered by study ID]

\begin{tabular}{ll}
\hline Study & Reason for exclusion \\
\hline Ahmadieh 2005 & RCT, not post-vitrectomy patients \\
\hline Asaria 2001 & RCT, post-vitrectomy patients, not for cataract surgery \\
\hline Batman 1999 & RCT, not post-vitrectomy patients, not cataract surgery \\
\hline Blankenship 1980 & RCT, not post-vitrectomy patients, not for cataract surgery \\
\hline DRVS 1985 & RCT or CCT, not post-vitrectomy patients, not cataract surgery \\
\hline Ehud 1988 & RCT, not post-vitrectomy patients, not for cataract surgery \\
\hline Ezra 2004 & RCT, not post-vitrectomy patients, not for cataract surgery \\
\hline Freeman 1997 & RCT, not post-vitrectomy patients, not for cataract surgery \\
\hline Haimann 1984 & RCT, not post-vitrectomy patients, not for cataract surgery \\
\hline Silicone Study 1992 & RCT for post-vitrectomy patients, not for cataract surgery \\
\hline
\end{tabular}

CCT: controlled clinical trial

RCT: randomized controlled trial 


\section{DATA ANDANALYSES}

This review has no analyses.

\section{A P P E N D I C E S}

\section{Appendix I. CENTRAL search strategy}

\#1 MeSH descriptor: [Vitrectomy] explode all trees \#2 MeSH descriptor: [Vitreoretinal Surgery] explode all trees \#3 (vitrectom* or post-vitrectom* or postvitrectom*) \#4 (vitreous surg* or vitreous resection* or vitreoretinal surg*) \#5 \#1 or \#3 or \#4 \#6 MeSH descriptor: [Cataract] explode all trees \#7 MeSH descriptor: [Cataract Extraction] explode all trees \#8 MeSH descriptor: [Capsulorhexis] explode all trees \#9 MeSH descriptor: [Phacoemulsification] explode all trees \#10 cataract* $^{*}$

\#11 lens*

\#12 (phakectom* or zonulolys* or catarectom*) \#13 (pha?oemulsif* or pha?o or Capsulor?hexis) $\# 14 \# 6$ or \#7 or \#8 or \#9 or \#10 or \#11 or \#12 or \#13 $\# 15$ \#5 and \#14

\section{Appendix 2. MEDLINE (OvidSP) search strategy}

1. Randomized Controlled Trial.pt.

2. Controlled Clinical Trial.pt.

3. (randomized or randomised).ab,ti.

4. placebo.ab,ti.

5. drug therapy.fs.

6. randomly.ab,ti.

7. trial.ab,ti.

8. groups.ab,ti.

9. 1 or 2 or 3 or 4 or 5 or 6 or 7 or 8

10. exp animals/ not humans.sh.

11. 9 not 10

12. exp Vitrectomy/

13. exp Vitreoretinal Surgery/

14. (vitrectom* or post-vitrectom* or postvitrectom*).tw.

15. (vitreous surg* ${ }^{*}$ or vitreous resection* or vitreoretinal surg*).tw.

16. 12 or 14

17. exp Cataract/

18. exp Cataract Extraction/

19. exp Capsulorhexis/

20. exp Phacoemulsification/

21. cataract*.tw.

22. lens*.tw.

23. (Phakectom* or Zonulolys* or catarectom*).tw.

Surgery for post-vitrectomy cataract (Review) 
24. (pha?oemulsif* or pha\#o or Capsulor?hexis).tw.

25. or/17-24

26. 16 and 25

27. 11 and 26

\section{Appendix 3. EMBASE.com search strategy}

\#1 'randomized controlled trial'/exp

\#2 'randomization'/exp

\#3 'double blind procedure'/exp

\#4 'single blind procedure'/exp

\#5 random*:ab,ti

\#6 \#1 OR \#2 OR \#3 OR \#4 OR \#5

\#7 'animal'/exp OR 'animal experiment'/exp

\#8 'human'/exp

\#9 \#7 AND \#8

\#10 \#7 NOT \#9

\#11 \#6 NOT \#10

\#12 'clinical trial'/exp

\#13 (clin* NEAR/3 trial*):ab,ti

\#14 ((singl* OR doubl* OR trebl* OR tripl*) NEAR/3 (blind* OR mask*)):ab,ti

\#15 'placebo'/exp

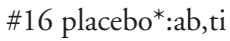

\#17 random*:ab,ti

\#18 'experimental design'/exp

\#19 'crossover procedure'/exp

\#20 'control group'/exp

\#21 'latin square design'/exp

\#22 \#12 OR \#13 OR \#14 OR \#15 OR \#16 OR \#17 OR \#18 OR\#19 OR \#20 OR \#21

\#23 \#22 NOT \#10

\#24 \#23 NOT \#11

\#25 'comparative study'/exp

\#26 'evaluation'/exp

\#27 'prospective study'/exp

\#28 control*:ab,ti OR prospectiv*:ab,ti OR volunteer*ab,ti

\#29 \#25 OR \#26 OR \#27 OR \#28

\#30 \#29 NOT \#10

\#31 \#30 NOT (\#11 OR \#23)

\#32 \#11 OR \#24 OR \#31

\#33 'vitrectomy'/exp

\#34 'vitreoretinal surgery'/de

\#35 vitrectom*:ab,ti OR postvitrectom*:ab,ti

\#36 (vitreous NEAR/1 surg*):ab,ti OR (vitreous NEAR/1 resection*):ab,ti OR (vitreoretinal NEAR/1 surg*):ab,ti \#37 \#33 OR \#34 OR \#35 OR \#36

\#38' cataract'/exp

\#39 'cataract extraction'/exp

\#40 'capsulorhexis'/exp

\#41 'phacoemulsification'/exp

\#42 cataract*:ab,ti

\#43 lens*:ab,ti

\#44 phakectom*:ab,ti OR zonulolys*:ab,ti OR catarectom*:ab,ti

\#45 pha?oemulsif* OR pha?o OR capsulor?hexis

Surgery for post-vitrectomy cataract (Review)

Copyright $\odot 2013$ The Cochrane Collaboration. Published by John Wiley \& Sons, Ltd. 
\#46 \#38 OR \#39 OR \#40 OR \#41 OR \#42 OR \#43 OR \#44 OR \#45

\#47 \#32 AND \#37 AND \#46

\section{Appendix 4. LILACS search strategy}

(Vitrectom\$ OR post-vitrectom\$ OR postvitrectom\$ OR “vitreous surgery" OR “vitreous surgeries" OR “vitreous resection” OR “vitreoretinal surgery" OR “vitreoretinal surgeries” OR MH:E04.540.960\$) AND (Cataract\$ OR Catarata\$ OR MH:C11.510.245\$ OR MH:E04.540.825.249\$ OR MH:E04.943.875\$ OR lens\$ OR Capsulorhexis OR Capsulorrexis OR Capsulorrexe OR Capsulorrhexis OR Phacoemulsif\$ OR Facoemulsif\$ OR Phakectom\$ OR Zonulolys\$ OR catarectom\$ OR Phakoemulsif\$)

\section{Appendix 5. metaRegister of Controlled Trials search strategy}

cataract and vitrectomy

\section{Appendix 6. ClinicalTrials.gov search strategy}

cataract AND vitrectomy

\section{Appendix 7. ICTRP search strategy}

cataract AND vitrectomy

\section{Appendix 8. PubMed search strategy}

\#1 ((randomized controlled trial[pt]) OR (controlled clinical trial[pt]) OR (randomised[tiab] OR randomized[tiab]) OR (placebo[tiab]) OR (drug therapy[sh]) OR (randomly[tiab]) OR (trial[tiab]) OR (groups[tiab])) NOT (animals[mh] NOT humans[mh]) \#2 (vitrectom*[tiab] OR post-vitrectom*[tiab] OR postvitrectom*[tiab]) NOT Medline[sb]

\#3 (“vitreous surgery” [tiab] OR “vitreous surgeries"[tiab] OR vitreous resection*[tiab] OR “vitreoretinal surgery”[tiab] OR “vitreoretinal surgery”[tiab]) NOT Medline[sb]

\#4 (\#2 OR \#3)

\#5 (cataract* $\left.{ }^{*}[\mathrm{tiab}]\right)$ NOT Medline[sb]

\#6 (lens*[tiab]) NOT Medline[sb]

\#7 (Phakectom*[tiab] OR Zonulolys*[tiab] OR catarectom*[tiab]) NOT Medline[sb]

\#8 (phaco*[tiab] OR phako*[tiab]OR Capsulorhexis[tiab] OR Capsulorrhexis[tiab) NOT Medline[sb]

\#9 (\#5 OR \#6 OR \#7 OR \#8)

\#8 (\#1 AND \#4 AND \#9)

\section{WHAT'S NEW}

Last assessed as up-to-date: 22 May 2013. 


\begin{tabular}{lll}
\hline Date & Event & Description \\
\hline 2 December 2013 & $\begin{array}{l}\text { New citation required but conclusions have not } \\
\text { changed }\end{array}$ & $\begin{array}{l}\text { Issue 12, 2013: Some sections of the review have been } \\
\text { updated including the 'Implications for practice' sec- } \\
\text { tion. }\end{array}$ \\
\hline 2 December 2013 & New search has been performed & Issue 12, 2013: Updated searches yielded no new trials. \\
\hline
\end{tabular}

\section{H I S T O R Y}

Protocol first published: Issue 1, 2007

Review first published: Issue 3, 2008

\begin{tabular}{lll}
\hline Date & Event & Description \\
\hline 5 May 2011 & New search has been performed & Issue 6, 2011: Updated searches yielded no new trials. \\
\hline 26 March 2008 & Amended & Converted to new review format. \\
\hline 27 September 2006 & New citation required and conclusions have changed & Substantive amendment. \\
\hline
\end{tabular}

\section{CONTRIBUTIONS OF AUTHORS}

Conceiving the review: $\mathrm{BSH}$

Designing the review: DVD, BSH

Co-ordinating the review: $\mathrm{BSH}$

Data collection for the review

- Designing electronic search strategies: CEVG Trials Search Co-ordinator, DVD, BSH, SG, SV

- Undertaking searches: CEVG Trials Search Co-ordinator, DVD, BSH, SG, SV

- Screening search results: DVD, BSH, SG, SV

- Organizing retrieval of papers: DVD, XW

- Screening retrieved papers against inclusion criteria: DVD, BSH, SV, XW

- Appraising quality of papers: DVD, BSH

- Extracting data from papers: DVD, BSH, SV

- Writing to authors of papers for additional information: DVD, BSH

- Providing additional data about papers: BSH, SG

- Data management for the review: SG, SV

- Entering data into RevMan: SG, DVD, SV

Surgery for post-vitrectomy cataract (Review)

Copyright @ 2013 The Cochrane Collaboration. Published by John Wiley \& Sons, Ltd. 
Analysis of data: BSH, DVD, SV

Interpretation of data

- Providing a methodological perspective: BSH, SG, SV

- Providing a clinical perspective: DVD, BSH, SG, SV

- Providing a policy perspective: BSH, DVD, SG, SV

Writing the review: DVD, BSH, SG, SV

Securing funding for the review: BSH, DVD

Performing previous work that was the foundation of the current study: BSH, DVD

Updating the review: BSH, DVD, XW

Guarantor of the review: DVD

\section{DECLARATIONSOF INTEREST}

None known.

\section{SOURCES OF SUPPORT}

\section{Internal sources}

- Research to Prevent Blindness Grant to Wilmer Eye Institute, USA.

- Retina Research Fund, Wilmer Eye Institute, The Johns Hopkins Hospital, Baltimore, USA.

\section{External sources}

- National Eye Institute, National Institutes of Health, USA.

Methodological support from Cochrane Eyes and Vision - US Project is funded by Grant 1 U01 EY020522-01

\section{INDEX TERMS}

\section{Medical Subject Headings (MeSH)}

${ }^{*}$ Cataract Extraction; Cataract [*etiology]; Quality of Life; Randomized Controlled Trials as Topic; Visual Acuity; Vitrectomy [*adverse effects]

\section{MeSH check words}

Adult; Humans 